\title{
CHANGING MINDS: EVERY FAMILY IN THE LAND - AN UPDATE W
}

The Changing Minds campaign was launched in October 1998 and you will have received a copy of the 'Declaration of Intent' setting out the aims and objectives of the campaign and inviting members to endorse it. We have already received nearly 1500 signatures. It is essential however to have the weight of support from the College membership behind us. If you have not returned the Declaration which was included in the recent Annual Meeting 1999 mailing, could I remind you to do so. (If you have mislaid it, please contact the Campaign Administrator.)

To promote the campaign, we are arranging a one-day event on Friday 21 May 1999 at the Society of Chemical Industry, 15 Belgrave Square, London SW1, entitled How the media perpetuate stigma, and how you can use the media to reduce it. There will be a nominal charge of $\mathrm{f} 25.00$ for the day. This will entitie you to a Campaign Promotional Pack with relevant materials to take forward activities at a local level. For a programme and booking form, contact Deborah Hart, External Affairs Department: Tel: 01712352351 ext. 127 e-mail: dhart@rcpsych.ac.uk.

A session updating the membership on the work of the campaign is also planned for the Annual Meeting 1999 in Birmingham, on the afternoon of Monday 28 June. We hope that you will be able to attend.
The campaign has already set in motion a number of projects targeting children and adolescents (chaired by Dr Susan Bailey); doctors, including mental health professionals (chaired by Professor Tom Arie); employers (chaired by Dr Graham Bell from Esso Petroleum Ltd), and the media (chaired by Dr Mark Salter and Dr Peter Byrne).

We have also established a small working group, chaired by Dr Tom Harrison, addressing the stigmatisation of people suffering from schizophrenia.

A major bit of news is that the Cooperative Bank has agreed to sponsor a campaign-related award in the British Design and Art Direction 1999 Student Awards. Students are invited to design a piece of print that will influence opinion formers in the media to change their attitudes towards mental health. The award will be given to the winning entry in June 1999 - so watch this space.

Several other ongoing projects include a cinema trailer and a video.

We would also remind members that seven booklets have been produced entitled 'Mental disorders: challenging prejudice', 'Depression', 'Anxiety', 'Schizophrenia', 'Alzheimer's disease and dementia', 'Anorexia and bulimia', and finally, 'Alcohol and other drug misuse'. Copies are available, free of charge, from the Campaign Administrator on receipt of an A5 sae (45p postage). An $A 3$ size poster has also been developed and is available as above, on receipt of postage stamps to the value of $31 p$.

We hope that you will continue to support this important initiative.

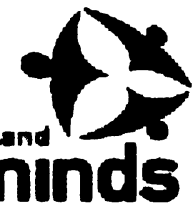

Campaign Administrator

Royal College of Psychiatrists

17 Belgrave Square, London SW1X 8PG Tel: 01712352351 , ext. 122 or e-mail: stigma@rcpsych.ac.uk 